\title{
O DESENVOLVIMENTO DO COMÉRCIO VIRTUAL E SUAS IMPLICAÇÕES NO ÂMBITO JURÍDICO.
}

Jairo Cleosmar Rodrigues Junior, Marcio França Teixeira

Universidade do Oeste Paulista - UNOESTE - Curso de Direito, Presidente Prudente, SP. E-mail: jairo_rodrigues00@hotmail.com

\section{RESUMO}

O presente artigo tem como objetivo discutir a expansão, bem como os benefícios da utilização do comércio eletrônico tanto na praticidade das compras e vendas, quanto no exercício das profissões que desencadeiam o acesso cada vez mais irrestrito de informações e serviços através da internet. Entendemos que a função principal do trabalho é a de explorar junto à jurisprudência, bibliografias e alguns artigos, as novas tendências mercantis, laborais e o acesso a serviços designados à população, tornando menos burocrática e mais simples a vida de milhões de pessoas e trazendo ao mercado de trabalho avanços oriundos de melhorias tecnológicas, principalmente sob a ótica cibernética.

Palavras-chave: Mercado. Internet. Avanços Tecnológicos. Serviços. Comércio Eletrônico.

THE DEVELOPMENT OF VIRTUAL TRADE AND ITS IMPLICATIONS IN THE LEGAL FRAMEWORK.

\section{ABSTRACT}

The Brazilian and world reality in regards to the exercise of professions triggers an, each time less restricted, access of information and services through the internet. The presented article's function is to explore the new trends in market, labor and access to services designated to the population, transforming the life of millions of people less bureaucratic and bringing, to the job market, arising advances of upcoming technologies, specially under the cybernetic optics.

Keywords: Market. Internet. Technological Advancements. Services. E-Commerce. 


\section{INTRODUÇÃO}

O artigo tem a intenção de dissertar a respeito da expansão em larga escala do ecommerce e a sua influência em vários segmentos da sociedade contemporânea, em especial no mercado de trabalho, na facilidade de se adquirir o produto desejado no âmbito virtual e na adequação da jurisprudência visando resolver ou evitar problemas oriundos dessa nova prática.

No contexto atual, o cenário do desenvolvimento tecnológico contribuiu para um grande aumento de paradigma na geração de ações com a finalidade de constituir um modelo com grande eficácia visando utilizar a internet como um poderoso recurso gerador de receitas. Este trabalho, portanto, visa entender os avanços tecnológicos oriundos do mundo virtual e como a sociedade passou a olhar para sua utilização, bem como o Direito precisou se adequar para garantir a harmonia e a resolução de possíveis litígios que passaram a surgir em virtude da atividade de compras virtuais.

\section{METODOLOGIA}

O presente artigo empregou pesquisas a doutrinas, pesquisas e periódicos virtuais relevantes na matéria objeto de estudo. Foi empregado o método dedutivo para sistematizarmos dados coletados a fim de cumprir o objetivo proposto.

A intenção principal do referido trabalho é a reflexão sobre os avanços tecnológicos, atingindo a sociedade contemporânea como um todo, entendendo assim como a internet possibilitou o surgimento de novas relações comerciais oriundas do comércio eletrônico, alterando inclusive, em alguns casos, o ambiente de trabalho, analisando também a importância do Direito como instrumento de harmonia social estabelecendo ou readequando normas para garantir que as novas práticas comerciais não sejam lesivas ou abusivas para nenhuma das partes, caminhando de um raciocínio lógico amplo, afunilando para o restrito, de uma forma dialética.

\section{RESULTADOS}

A evolução das ações de compras e vendas no ambiente eletrônico faz surgir uma problemática, pois a partir do desenvolvimento desse mercado econômico, certo ou não, a atividade virtual tem aumentado potencialmente suas vendas virtuais e criando empregos, os quais pequenos empresários e funcionários não necessitam estar em um ambiente de trabalho, podendo exercer suas respectivas funções em ambientes alternativos, no entanto, é de grande importância que o Direito consiga se adequar de tal forma a essa nova realidade para que exerça a sua função de regular efetivamente as novas demandas vinculadas ao e-commerce, impedindo assim futuros litígios entre as partes envolvidas, ainda que por meio virtual.

Devido aos avanços tecnológicos, o mercado virtual se tornou um importante instrumento de compras e possibilidade de novas formas de se exercer uma profissão, gerando assim novas oportunidades de emprego, favorecendo o desenvolvimento social e diminuindo o número de desempregados no Brasil, por isso, entende-se a importância de se abordar e discutir os benefícios e consequências dessas novas interações.

$\mathrm{O}$ presente artigo busca entender como o e-commerce se tornou uma ferramenta comercial tão poderosa, bem como os avanços tecnológicos tendem a facilitar o acesso a serviços e trabalhos na sociedade como um todo, possibilitando a geração de novos empregos e aumento da produção, gerando mais lucro. Para isso, é essencial a adequação da norma jurídica para não haver litígios ou que parte alguma seja prejudicada em meio à relação social abordada, podendo ela ser de natureza trabalhista ou comercial. 


\section{DISCUSSÃO}

O processo de desenvolvimento da internet pode ser considerado como um marco de grande evolução na história da humanidade. É possível considera-lo como fator icônico no curso da modernidade, visto que muitos pesquisadores concordam com o fato de que a terceira Revolução Industrial iniciou-se com o advento da eletrônica após o fim da Segunda Guerra Mundial (1939-46) tendo os Estados Unidos como país em que a chamada rede mundial de computadores foi criada.

Os anos que se sucederam até chegarmos ao século XXI foi de intenso desenvolvimento, tendo a rapidez com que os meios eletrônicos foram se desenvolvendo como sua principal característica. Atualmente, podemos fazer vários serviços e compras utilizando-se da internet em apenas alguns minutos, algo nunca antes imaginado nos anos 90 .

Em sua obra A Galáxia da Internet. Reflexões sobre a Internet, os negócios e a sociedade, Manuel Castells (2003, p.7) argumenta:

A Internet é o tecido de nossas vidas. Se a tecnologia da informação é hoje o que a eletricidade foi na Era Industrial, em nossa época a Internet poderia ser equiparada tanto a uma rede elétrica quanto ao motor elétrico, em razão de sua capacidade de distribuir a força da informação por todo o domínio da atividade humana. Ademais, à medida que novas tecnologias de geração e distribuição de energia tornaram possível a fábrica e a grande corporação como os fundamentos organizacionais da sociedade industrial, a Internet passou a ser a base tecnológica para a forma organizacional da Era da Informação: a rede. Uma rede é um conjunto de nós interconectados. A formação de redes é uma prática humana muito antiga, mas as redes ganharam vida nova em nosso tempo transformando-se em redes de informação energizadas pela Internet. As redes têm vantagens extraordinárias como ferramentas de organização em virtude de sua flexibilidade e adaptabilidade inerentes, características essenciais para se sobreviver e prosperar num ambiente em rápida mutação. É por isso que as redes estão proliferando em todos os domínios da economia e da sociedade, desbancando corporações verticalmente organizadas e burocracias centralizadas e superando-as em desempenho. Contudo, apesar de suas vantagens em termos de flexibilidade, as redes tiveram tradicionalmente de lidar com um grande problema, em contraste com hierarquias centralizadas. Elas têm tido considerável dificuldade em coordenar funções, em concentrar recursos em metas específicas e em realizar uma dada tarefa dependendo do tamanho e da complexidade da rede.

O advento das compras virtuais internacionais como novas tendências mercadológicas trouxe à tona um novo assunto de grande relevância, a forma como o Direito iria se adequar visando garantir que essa nova prática comercial pudesse ser resolvida de forma justa e sem haver prejuízos principalmente por parte do consumidor em casos de litígios. A legislação teve de ser reformulada para atender as novas demandas de produtos que pudesse ser entregues com vícios ou que simplesmente não chegassem ao consumidor, visto que, até então, o fato do comércio não ter atingido tal patamar, o Código de Defesa do Consumidor e o Direito Civil se apresentavam como instrumentos normativos mais eficazes para resolver litígios de tal natureza.

A internet comercial chegou ao Brasil no ano de 1995. Porém, com sua conexão discada, de difícil acesso e extremamente cara à época, por precisar de um micro computador, além de poucos recursos dentro da rede foram os principais fatores para a impopularidade do recurso que posteriormente mudaria o nosso meio de viver. Aos poucos a internet foi ganhando popularidade, novos meios de acesso à rede de forma mais rápida e barata. O boom das redes sociais fez com que o brasileiro entrasse de vez no mundo cibernético. Segundo Avanze (2015):

No âmbito doméstico, vimos computadores "tubões" entrarem na internet pela primeira vez, com uma conexão discada, lenta e instável. Não demorou para que logo começássemos a usar a rede para conhecer pessoas novas ou mesmo para nos comunicarmos com as que já conhecíamos no mundo real. Em especial os brasileiros, logo se renderam ao advindo das mídias sociais. 
Não teve mais volta, o brasileiro conhecera um novo modo de se comunicar, fazer amizades e trabalhar. O home office virou uma tendência. Atualmente, diversas multinacionais praticam e incentivam tal modo de trabalho, visando melhorar a produtividade, como a titulo de exemplo temos a LocaWeb. Nesse contexto, expõe Ladeia (2016):

Na Locaweb, marketing, tecnologia e comercial são elegíveis ao trabalho remoto - que não é oficialmente institucionalizado, mas totalmente negociado entre os funcionários. Cerca de $30 \%$ dos funcionários praticam o home office. Segundo a empresa, o fato de atuarem em tecnologia faz com que sejam naturalmente inclinados a admitir o trabalho remoto - que é praticado desde o início das operações da empresa.

Todo esse arsenal de informações, tecnologias e praticidade que foi possível alcançar devido aos avanços dos sistemas informacionais e do comércio na grande rede, fez com que as empresas físicas também começassem a disponibilizar seus serviços no meio eletrônico, garantindo ao cliente a escolha da compra nas lojas físicas ou utilizando algum equipamento eletrônico.

Nesse aspecto, podemos dizer que já era imaginável grandes mudanças e adequações devido a grande competitividade do mercado comercial no século XXI, onde empresas de grande e pequeno porte também devem estar atentas ao comércio internacional.

NAKAMURA (2011, p.15) resume a adequação das empresas ao ambiente virtual de comércio:

O Comércio Eletrônico trouxe as empresa ferramentas com novas tecnologias, para realizar negócios eletronicamente com maior eficiência, rapidez e menor custo. Para um negócio tornar-se bem sucedido, é de extrema importância saber utilizar da maneira adequada à tecnologia disponível no mercado e também que seja apropriada aos consumidores do mercado extenso.

A jurisprudência também teve que se adequar para resolver litígios dessa nova categoria comercial. Em virtude do boom das compras virtuais, começaram a surgir diversas ações e demandas da ordem do comércio virtual.

Visando garantir os direitos do consumidor, o Código de Defesa do Consumidor inovou com a desistência que pode ser solicitada após sete dias (NUNES, 2016).

Nesses termos, Nunes (2016) expõe:

O CDC estabeleceu o direito de desistência a favor do consumidor. A intenção da lei é proteger o consumidor nesse tipo de transação para evitar compras por impulso ou efetuadas sob forte influência da publicidade ou do pessoal do telemarketing sem que o produto esteja sendo visto de perto ou o serviço possa ser testado.

Esse prazo garantido pela lei é de sete dias e chama-se prazo de reflexão.

Se nesses sete dias o consumidor se arrepender da compra, pode desistir pura e simplesmente. $\mathrm{O}$ arrependimento não precisa ser justificado. Não é preciso dar qualquer satisfação. Basta desistir.

A contagem do prazo dos sete dias inicia-se quando do recebimento do produto.

Existem fornecedores que oferecem prazos maiores de arrependimento: dez, quinze e até trinta dias. Nesses casos, o prazo de reflexão fica automaticamente ampliado, conforme for a oferta.

E, visando dar eficácia ao contido no art. 49, o decreto 7.962 referido trouxe para o sistema uma série de outras determinações específicas. Numa delas (art. 5o "caput"), reforça que o fornecedor deve informar, de forma clara e ostensiva, os meios adequados e eficazes para o exercício do direito de arrependimento pelo consumidor. E n'outra ( $\S 1$ o do mesmo art. 5ㅇ) disciplina aquilo que já estava inserido como garantia no CDC: que o consumidor poderá exercer seu direito de arrependimento pela mesma ferramenta utilizada para a contratação, sem prejuízo de outros meios disponibilizados.

Uma boa novidade trazida pelo Decreto é a determinação de que o fornecedor envie ao consumidor a confirmação do recebimento da desistência imediatamente após a manifestação do arrependimento (§ 4으, art. 5ㅇ). 
No ano de 2013, entrou em vigor o Decreto no 7.962 com o objetivo de estruturar os critérios para o bom andamento do e-commerce no Brasil. A ideia principal foi regulamentar e definir normas para a atividade de compras coletivas.

A elaboração do Decreto Lei acima mencionado exemplifica a importância do Direito estar em constante evolução e pronto para se adequar às mudanças e novas demandas criadas pela sociedade contemporânea de modo a garantir a resolução de conflitos de qualquer instância, garantindo assim a convivência harmônica e pacífica, e nesse caso especificamente, da manutenção da Justiça e da ordem nas práticas comerciais independentes de suas formas e natureza.

Considerando a evolução quanto ao mercado e as necessidades humanas com o avanço tecnológico, a informação chega cada vez mais rápida ao indivíduo. Em um mundo onde chamar taxi, pedir comida, comprar roupas ou produtos e adquirir serviços é feito de forma online, cada vez mais cairá o habitual modelo existente a muitos anos.

Analisando esse contexto, pode-se afirmar que estamos na era da informação e vivenciando esta transição imersos ao novo modo de comportamento humano, dentre esses, o abandono do ambiente físico para o exercício da profissão, como mencionado anteriormente.

\section{CONCLUSÃO}

Como é notório ressaltar, a evolução quanto ao mercado e as necessidades humanas com o avanço tecnológico, possibilitando as informações chegar cada vez mais rápida ao indivíduo.

Analisando esse contexto, pode-se afirmar que estamos na era da informação e vivenciando esta transição, imersos ao novo modo de comportamento humano, dentre esses, o abandono do ambiente físico para o exercício da profissão.

Nesse sentido, a utilização do comércio eletrônico como importante e poderoso mecanismo de compra e venda no âmbito virtual tornou mais simples e cômoda a vida na sociedade moderna, visto que as compras são efetuadas de forma mais rápida e eficiente. Além disso, diminui o tempo de espera nos caixas de pagamento das lojas físicas.

O presente trabalho constatou que o regime jurídico do processo inerente às práticas comerciais e as novas formas de trabalho demonstram um grau importante de harmonização, coordenação e compatibilidade enquanto à relação social existente entre as pessoas (sejam elas físicas ou jurídicas) envolvidas, devem estar muito bem fiscalizadas pelo Poder Judiciário.

O estudo conclui que os avanços tecnológicos se tornaram um importante instrumento de compras e possibilidade de novas formas de se exercer uma profissão, gerando assim, novas oportunidades de emprego, favorecendo o desenvolvimento social e colaborando para diminuir o número de desempregados no Brasil.

\section{REFERÊNCIAS}

AVANZI, Dane. 20 anos de internet no Brasil: da rede discada à internet das coisas. Disponível em: http://www.abranet.org.br/Artigos/20-anos-de-internet-no-Brasil\%3A-da-rede-discada-a-internetdas-coisas-666.html? UserActiveTemplate=site. Junho. 2015

CASTELLS, Manuel. A galáxia da Internet: Reflexões sobre a internet. ZAHAR. 2003.

NAKAMURA, André Massami. Comércio eletrônico: Riscos nas compras pela internet. FACULDADE DE TECNOLOGIA DE SÃO PAULO. SÃO PAULO, 2011.

NUNES, Rizzatto. O comércio eletrônico e o Direito do Consumidor. Disponível em: $<$ http://www.migalhas.com.br/ABCdoCDC/92,MI249828,21048

O+comercio+eletronico+e+o+Direito+do+Consumidor>. Dezembro de 2016. 
LADEIA, Barbara. 8 empresas que permitem (e estimulam) o home office. Disponível em: http://exame.abril.com.br/negocios/8-empresas-com-politicas-home-office/. Setembro. 2016. 